JOURNAL OF SECURITY AND SUSTAINABILITY ISSUES

ISSN 2029-7017 print/ISSN 2029-7025 online

2021 Volume 11

https://doi.org/10.47459/jssi.2021.11.16

\title{
THE ROLE OF THE "REFLECTIVE PRACTICE" COMPETENCE IN THE PROFESSIONAL TRAINING OF PRISON SERVICE OFFICERS
}

\author{
Mariusz Malinowski \\ Academy of Justice, 50 Wiśniowa Street, 02-520 Warsaw, Poland \\ E-mail: mariusz.malinowski@swws.edu.pl
}

Received 15 October 2020; accepted 10 April 2021; published 30 June 2021

\begin{abstract}
This paper presents the model of "reflective practice" according to D. Schön's conception, with special regard to the phenomenon of simultaneous thinking in action, which was applied in the implementation of a pilot postgraduate study program for the future managing staff of penitentiary units. The author describes theoretical sources of inspiration for the training of officers to the profile of professional competence defined as the "Reflective Practitioner". The presented approaches to education and training are based on the trend of reflective practice methodology that could be quickly implemented in daily professional practice of experienced and newly trained prison service officers.
\end{abstract}

Keywords: reflective practice; adult education methodology; penitentiary and security sciences; work education; professional training of officers; simultaneous thinking and action; reflective practitioner.

Reference to this paper should be made as follows: Malinowski, M. 2021. The role of the "reflective practice" competence in the professional training of prison service officers. Journal of Security and Sustainability Issues, 11, 195-203.

https://doi.org/10.47459/jssi.2021.11.16

JEL Classifications: F0

Additional disciplines: security

\section{Introduction}

The Polish prison service looks for new inspirations for the creation of professional attitudes consistent with the requirements of modern times, which become more and more different from formerly established routine methods of prison officer education and training. Recently established as the first school of higher education of the ministry of justice in the history of Poland, the Academy of Justice aims to bring about a significant transformation in the Polish penitentiary system. One of the modernisation elements was the inspiration brought by the adopted conception of "reflective practice". The competence profile model elaborated by D. Schön, the author of the concept "Reflective Practitioner", was put to use in the first place. Schön's proposal was implemented in a pilot postgraduate study program in the field of management addressed to the personnel of penitentiary services throughout Poland who will have an opportunity to participate in promotion to managing positions in penal institutions in the nearest future. The first experiences in the use of the reflective educational approach to the professional training of competent professionals in the staff of prison service officers is only the beginning of the construction of a model of studies based on theories of multiple intelligences that is closely connected with the essence of the conception of reflective practice. This paper gathers and presents selected theoretical sources that provided fundamentals for the adopted guidelines that have been used in the pilot course regarding

\footnotetext{
1 This concept was capitalised as a method of indicating a specific model elaborated by D. Schön, because it has become so popular that it exists in various semantic scopes elaborated by other researchers.
} 
the development of managerial competitions creating an officer perceived as a "reflective practitioner".

\section{Reflection as a practical means of effective action}

In his two world-famous books that are classic works on reflective practice today, Schön ${ }^{2}$ presents his reflections based on long-year research on this phenomenon, focusing on what makes practical actions of high-class professionals usually "adequate" and "effective". Schön's research focused on such professional groups as architects, consultants, academic teachers or psychotherapists, but his reflections are applied to many different professions today.

Schön was the first to define the professional profile using the term "Reflective Practitioner" and, therefore, is regarded as its originator. Adding the concept and idea of "professional artistry" to this term, it is believed that Schön has the "controlling package" of theoretical interpretations dealing with the issue of "work with people" in the existing rich trend of the field and discipline broadly defined as reflective practice. (Schön, 1984)

In the opinion of Schön, any activity related to the specifics of "work with people" requires a separate and adequate model of action, because it is connected with the natural context of the conflicts of value and the conflicts of interest, which is specific to this sphere of human interactions. In his view, no mechanistic model of technical rationality with its relevant package of elaborated standards and procedures may be inadequate in the practice of actions involving various types of reaction and references of interpersonal mutual impacts that are unique, complex, variable and insecure in terms of character.

On the basis of his research, Schön elaborated a detailed concept of "reflection-in-action" as an example of a specific "theoretical skill" and, at the same time, "practical ability" being a special kind of professional proficiency of a high-class professional that he defined as a "Reflective Practitioner". He tried to describe, present and recommend the phenomenon noticed by him thinking and acting almost simultaneously on a running basis; when a given professional simultaneously thinks and acts and acts and thinks. It is this kind of theoreticalpractical thought - closely and simultaneously combined with the action being performed. Almost at the same time, although - out of necessity - in a naturally separate mode, thinking and acting (even in microseconds of differences of mental acts), it consequently integrates "simultaneously" "decision thinking" with "executive thinking" into one process of deliberate activity.

It is important to add that Schön believed that this specific skills is not an inborn gift available only to the chosen few (e.g., such as a musical ear and musical skills), but this kind of professional action can be learned through practice, exercise and training. Thus, in conditions of formal education, it is possible to train and improve professionals within the model of the "Reflective Professional" who will be able, in objective circumstances, to work out and elaborate its own individual style of action marked by the ability to perform with distinct features of effective efficiency.

When creating and implementing, under the Postgraduate Study Program being performed by the Academy of Justice, a management education program, e.g., on the detailed topic of solving problems in crisis situations; we deliberated in a project $\&$ implementation team how to help prison service employees develop a reflective practical approach that could be implemented both in their daily or extraordinary penitentiary practice.

Looking at the phenomenon of "reflective practice" from an educational viewpoint, it is an interesting methodological tool used in adult training courses where the emphasis is put on gaining competences of continuous self-education and self-improvement aimed at improving daily professional practice. Here, in the acquisition of new knowledge and skills aimed at effective action, we can recommend and apply the suggestions made by Schön, who proposes the pragmatic use of techniques connected with "reflection-on-action" and "reflection-

2 Here I refer to two canonical works by Schön: Schön D., (1984), The Reflective Practitioner. How Professionals think in Action?, Basic Books, New York. Schön, D. (1987). Educating the reflective practitioner: Toward a new design for teaching and learning in the professions. San Francisco: Jossey-Bass. 
in-action" that form the professional attitude and mentality in the Reflective Practitioner model. While spontaneous reflection is a natural thing - people usually think about their actions in order to change their ways of behaviour, "reflective practice" is a formalised process of critical thought that combines acquired knowledge with actions being undertaken. The practice of action in this model tries to implement new solutions of matters creating improved behaviours in general life situations and professional situations.

The methodology of "reflection-on-action" focuses our attention on the examination of our previous experiences. We attempt and try to determine which of the completed activities were effective and correct enough to be useful in the future. The methodology of "reflection-in-action" focuses our attention on decision thinking at the moment when we have to direct what we do.

Reflective deliberation and consultancy upon decision thinking that organised the performance of actions being undertaken becomes a method of work that constantly regulates the estimation of the best possible and still inherently valid ways of effective action. Reflective practice becomes a competence of useful way of thinking about the practice of effective problem solving, particularly with regard to new unpredictable ways for existing standards and procedures for adopted actions. The attitude concerning the acceptance of reflectiveness as a means of practical action is always open to undertaking action in any case of anomaly or crisis situation. Why? Because its foundation is the "metaphysical" theoretical cognitive belief that the surrounding REALITY is always richer than our even fullest knowledge about it, including our beliefs and any standardised organisational procedures. It seems that also the penitentiary infrastructure is not a definitely established "reality" of the civilisational product and requires the constant creation of a new concept of knowledge about it, because it is also an unstable structure of certain facts and theories and procedures describing it. It is a "living", "flexible", "dynamic", procedural and experimental zone of cultural social reality. The existing state of "knowledge" about the infrastructure of the penitentiary system covers both many ambiguities, inconsistencies and oppositions on the one hand and sets of empirically observed facts and emotions on the other hand. Thus, it is of interest that the practice of educating and training prison service officers turns into an active process of obtaining and acquiring this kind of reflective and, in its new sense, practical KNOWLEDGE that would support skilful performance, the KNOWLEDGE that results and manifests itself in the phenomenon of "INTELLIGENT ACTION".

The model of "reflection-in-action" refers to the details of the process when, in a new situation (unknown with regard to performance so far), we stop and reflect, on a current basis, on the nature of this problem situation and almost simultaneously undertaking some kind of action. When we face new, not fully familiar problems during our actions, we create ad hoc procedures for their solution - this kind of activity is usually defined as a "trial and error method". The adopted ways of seeking solutions are attempts - however, they are not random actions, because they employ our "critical reflection" - the reflection that creates results for each attempt that constitute grounds for further attempts to act. It is a conscious model of inquiry consisting of sequences of "moments" of reflection in the "reflection-in-action" process.

In its peculiarity, "reflection-in-action" is often the first step to questioning the current and used state of knowledge about action along with all inherent assumptions, procedures and rules. Reflection is a specific moment for a "mental problem situation" - the moment of "critical questioning" of the current state of procedural knowledge, which may often lead and does lead to the reconstruction of our current views on the question of professional attitudes and, in general, ways of understanding things.

What makes "reflection-in-action" different from other possible types of reflection, is primarily the important emergence of a sign of mental activity that is of "immediate significance for the performance of action". The reflected solution of the problem becomes immediately an acceptable kind of factual performance of undertaken tasks. In the opinion of Schön, a qualified practitioner is able to combine skilfully "reflection-in-action" and efficient performance into one whole.

On that occasion, Schön notices and points out one subtle yet meaningful fact: the very ability to be an efficient 
"Reflective Practitioner" does not have to go hand in hand with the skill of telling about (reporting on) "how He does it", because it is often a sort of the practitioner's "tacit knowledge". This is usually irritating for empirical researchers with a technical and rational attitude, who would like everything to be subject to a retrospective and analytical type of reporting. Of course, it is good if a reflective practitioner in his "reflection-on-action" is able to describe and talk in a more accurate or at least indicative way about the process of arriving at the right solutions that he reached when solving the issue in question. But that is another matter.

Another interesting issue undertaken by Schön in his considerations is unquestionably what he presented with regard to such method of practical thinking and action where the specifically perceived role and nature of "improvisation" is an important issue. In his view, it is the "heart" of the response of professionalism to unforeseeable practical problems that we may experience. Schön makes an analogy to "jazz improvisation", in which genuine musician can improvise; this is a distinctive feature of their professional artistry. These musicians listen to themselves and to their musical partners both during team and solo performances. They can sense their own path in the performance of music. Within the scope of a mutually played piece of music, they can mutually differentiate, combine, detach again and constantly create new combinations of a basic set of musical figures within the scope of a scheme or structure: rhythm, melody, development of harmony that maintains the coherent whole of a music standard or other piece being played.

By way of another analogy, Schön compares the "improvisation" process presented above to conducting all daily casual and professional conversations. He believes that in a good conversation - which is predictable in some aspects and unpredictable in others - interlocutors undertake and develop topics of conversation and pursue threads from the repertoire of things to talk about. Such conversations are a kind of verbal team "improvisations". Sometimes such a conversation gets into conventional routine (jibber-jabber) and develops according to the pace and rhythm of interaction so that participants seem to work out the content of conversation together without conscious reflection. In other situations, surprises and anomalies may happen - we deal with turns of conversation that may develop in various directions, but interlocutors come across relevant strategies of expression on a current basis. And these new threads of conversation may open a new prospect for further conversations. (Schön, 1987).

Referring to the nature of "improvisation" as a way of seeking the diversity of solutions within the scope of current standards or procedures results in a sort of mental opening to the novum in its broad sense for professionally treated practice. It provides, in some sense, conceptual validation for undertaking inspiring questions (within the limits of acceptable "improvisation") about what kind of structure is actually expected and required, how it is established or how variations of any kind can arise within and around it, such as new better working procedures or sometimes maybe also new worse procedures...

\section{Challenges of "professional artistry"}

Becoming a "Reflective Practitioner" as a result of working on oneself through formal training, self-study and self-improvement is a difficult task, but many find this process equally interesting and fascinating. The elaboration of relevant personal skills necessary for a deeper understanding of processes decisive for the improvement of one's own effectiveness in one's profession and personal life is a task for those to whom the idea of striving for "professional artistry" may be appealing. It is a broadly understood set of competences concerning developed mental abilities of improved multiple intelligences and a character of personal attitude that is sensitive to striving for values related to professionalism.

Whether we reach the stage of efficient action on the level of "professional artistry", depends on many factors, such as attitude to the nature of action - i.e., the perspective from which we want to perceive it. The English researcher Della Fish, one of more active followers of the conception of reflective practice implemented initially in the Schön model, gathered and elaborated the understanding of approaches to action in the form of dichotomy: an approach to action in its broad sense as a primarily scientific (technical and rational) activity on the one hand and as one of the arts requiring creative actions on the other hand (Fish, 1996). She presented a 
developed set of statements in the form of an ordered list of dichotomies marked with a thick line for the purpose of highlighting them and making them as expressive as possible. You can find them below:

1. Science seeks principles, laws and rules; Art starts where rules fail and prefers directions.

2. Science uses diagnoses, analyses and formulas; Art offers interpretations of search.

3. Science applies schedules and employs strict planning; Art prefers experience and spontaneity.

4. Science offers mainly skills and information to learners; Art perceives models and structures as measures that facilitate learning.

5. Science sticks to repetitive procedures; Art enters into improvisation with ease.

6. Science requires finite effective systems; Art leaves room for imagination. (Incidentally, this does not mean that creativity and imagination are absent in science).

7. Science may reduce all learners to one dimension by highlighting similar aspects of procedures; Art will expand differences through pressure on individual interpretations and creativity.

8. Science analyses tasks for the ease of deciding what the learner will need; Art suggests perceiving oneself as a learner.

9. Science perceives people as puppets and passive recipients; Art sees them as negotiators of new senses and interpretations.

10. Science refers to motivation, feedback and failed input; Art refers to human relations and responses.

11. Science defines learning as something that comes from an effective teacher; Art understands learning as something not logically related to teaching.

12. Science perceives knowledge as static, achievable and absolute; Art regards knowledge as a temporary and dynamic thing that provides only a point of support.

13. Science is based on knowledge about teaching and learning taken from such scientific disciplines as psychology, sociology and linguistics; Art is based on knowledge that is an aftermath of literature, history and philosophy.

14. Science assumes that Theory (of Education) is a scientific theory; Art allows theory to remain personal created by compilations of a range of humanities, including literature, art, history, autobiography and certain trends in sociology.

15. Science refers to goals and behaviourally defined indicators; Art prefers intentions.

16. Science refers to feedback loops; Art listens closely to shades of expressions.

17. Science refers to reinforcement and manipulation; Art prefers the skill of understanding human beings and their actions and working with them rather than on them.

18. Science proposes formulas; Art provides directions.

19. Science perceives education as supported by scientific (industrial) management; Art perceives its reinforcement by being sensitive to values in people and through the development of self-management and selfappraisal.

20. Science contributes atomistic and analytical thinking to education; Art uses means of critical reflection.

The above list may become a kind of protocol for all those who will want to enter the path of personal professional improvement in the model of professionalism considering the will of being an artist in the craft of one's profession.

\section{4. "Reflective Practitioner" as a goal of improvement}

According to Schön, striving for professionalism in the model of becoming a Reflective Practitioner should be based on interpreting the situation by going back to the previous experiences and the current state of one's formal knowledge to enable the improvement of further professional practice. This reflection on action has its stages of construction and reconstruction of one's current personal skills and knowledge for the purpose of creating further new feasible and practised "personal theories" of practical action. Interpreted in this way, the reconsidered, thought-out and rationalised policy allows us to "stand back" and go beyond the established frameworks, standards and procedures to recognise - with a fresh eye - other potential new contexts in the existing "formulas" for states of affairs and to notice the features that give rise to new innovative inspirations for action. 
In each implemented form of professions, the "Reflective Practitioner" tries to combine theoretical knowledge with a high degree of practical feasibility with the continuous reflective training of professional mastery.

The "Reflective Practitioner" continuously strives to reach the state of "proficiency", "practical orientation" and "knowledgeability" in specific fields of professionalism.

Schön asserts that effective practitioners can reveal and specify whole sequences of processes, regularities and procedures that occurred in their actions and can define values, beliefs and "personal theories" to which they adhered. He stresses that these are only certain attempts to provide explanations, certain linguistic structures clarifying something that should actually be called their personal "spontaneous form of intelligence". All presented descriptions usually refer within their primary scope to static categories interpreting facts and procedures, whereas this unique "knowledge-in-action" is always a dynamic structure.

The need to make a conscious reflection concerning resolute action to be taken usually emerges in reaction to the shock caused by the existing anomaly in situations where we usually followed predetermined routine measures. New situational elements faced by an experienced practitioner - whether he wants to or not, he must consider and reflect upon them again in order to take relevant action with the most correct possible variants avoiding risk - wrong or simply inadequate performances. Faced with such a necessity, the "Reflective Practitioner" stops for a while in the middle of action and reflects upon what to do next. Without interrupting his action, he can also "think on the run" and reflect on a running basis upon what to do next and tries to modify his actions as correctly as possible. In the first case, it is the aforementioned "reflection-on-action" and in the second case, it is "reflection-in-action". The biggest novum proposed by Schön is this "proficiency" of thought, which simultaneously combines thinking how to act and thought-out action into one implementation process. The undertaken activities consisting of solution testing and search sequences are a fully dynamic process in which current strategies become restructured and a new interpretation of necessary correct action emerges. Schön calls this process the reframing of issues. He asserts that a capable master practitioner is able to modify his action in his profession after a few seconds from the moment of choosing a specific type of solution and to fully integrate reflection and action.

For professionals, the situation "reframing" process means such concentration of thought that allows them to "listen and watch" in a new different way where the observation of the situation is more interpretative than analytical. (Gołębniak, 1998).

An important conclusion made by Schön is the statement that this kind of skilful reflective practice can be learnt, as we have written above. This involves the creation of circumstances for gaining a specific form of self-awareness in formal training and all kinds of independent study. Such actions have been undertaken also within the aforementioned postgraduate study course being implemented by Academy of Justice in Warsaw. The creation of reflective self-awareness in a prison service officer is based on a number of such factors as:

- increasing a sense of personal professional subjectivity (sovereignty);

- recognition of the existence of personal influence in the field of broadly understood professional infrastructure;

- the assumption of self-control for one's professional activities in both routine and unforeseeable situations; - the development of sensitivity to "hidden programs" - the actions that are actually implemented rather than those that are only declared in public;

- the increase of demand for self-reflection skills;

- attempting to enlarge the personal repertoire of styles of action with new knowledge and skills.

After everything that has been presented so far, let us focus our cognitive attention on the very phenomenon of reflection by giving more details about what it is or, using a different approach, by giving more details about how it can be interpreted in the most general sense.

The Anglo-Saxon tradition, in which the opinion on reflection presented by Schön seems to be rooted, may have its source in reflections presented on that subject by John Dewey in his book How We Think. In this work, 
the issue is interpreted as follows: 'Reflection is turning a topic over in various aspects and in various lights so that nothing significant about it shall be overlooked-almost as one might turn a stone over to see what its hidden side is like or what is covered by it. Thoughtfulness means, practically, the same thing as careful attention; to give our mind to a subject is to give heed to it, to take pains with it. In speaking of reflection, we naturally use the words weigh, ponder, deliberate - terms implying a certain delicate and scrupulous balancing of things against one another. Closely related names are scrutiny, examination, consideration, inspection-terms which imply close and careful vision, ' writes Dewey. (Dewey, 1988)

In general approaches specific to many human disciplines, reflection as such has many functions, the most visible of which is this cognitive intellectual perception that allows us to notice new facts and experiences and to rework the previous facts and experiences in a different manner.

Reflection as a thought concentration process allows us to control sources and the manner of acquiring new knowledge, at the same time maintaining the critical attitude to the knowledge we have acquired so far.

Reflection has an "auto-cognitive" function serving as consideration over our own beliefs, habits or behaviours and can sometimes serve as a basis for gathering personal knowledge about ourselves.

Reflection has also a wisdom function that allows people to maintain axiological and normative standards of existence.

Reflection has a function that puts acquired data in order and allows us to define clearly our attitudes to specific issues. It allows us to clarify or explain a specific situation or event.

As a result of practised reflection, we can acquire new experiences or reconfigure the experience we have gained so far.

Reflection fulfils also an auto-corrective and modifying (in the most general sense - corrective) function.

Creating a sort of list, we can say that reflection has the following group of "self-cognitive" functions at its disposal:

- self-awareness,

- self-observation,

- self-description,

- self-knowledge,

- self-definition,

- self-cognition,

and the following group of "self-decisive" functions:

- self-determination,

- self-control,

- self-discipline,

- self-denial,

- self-assessment,

- self-criticism,

- self-composure,

- self-ownership.

In philosophic approaches, reflection is usually defined as a type of reality-oriented discursive thinking; primarily, however, reflection is the orientation of thinking towards one's individual experiences, conditions and mental dispositions. Thus, reflection is a sort of "internal perception" when it refers to ourselves; when directed outside, it forms a pursuit of the conceptual capturing of the world. 
In educational fields, reflection is usually perceived as a process that leads to the potential internal (personality) transformation of the human being by means of self-corrective motivation aroused by it and sometimes also leads to the modification of individual behaviours.

Reflection is a very important culture-forming and civilisational factor, because the reflection process encompasses the cognitive objectivization of what surrounds us and the formulation of what determines our subjective perception of things and matters. This reflective subjectivism is closely interconnected and plays an important role in the created processes of objectifying ourselves and the surrounding world and social reality.

Reflection as a form of concentrated thought is often a source of formation of the mental attitude in us that resists certain thought conventions and stereotypes and generally stimulates our reflective self-criticism.

For the author of this article, reflection is specifically something that approaches thinking not as blue-sky activity, but as a definitely practical issue; even if "reflective thought" is an invisible phenomenon, the consequences of this specific - more or less reflective - thinking can be clearly visible and perceptible. Thus, reflection and reflectiveness is not only the domain of pure contemplation or meditation of oneself and the world - it is a practical domain in the strict sense that engages in considerations over thought-out, deliberate, sensible and just action...

\section{Conclusions}

Attempts made by the Academy of Justice to identify competence gap areas existing among the staff of professionally active prison service officers showed certain deficits of reflectiveness leading to routine attitudes based primarily on highly formalised procedures which do not always seem adequate to dynamically changing circumstances of the present-day social reality. For this reason, the scope of education and training of the penitentiary system staff was enlarged with a model that had not been used until then - "reflective practice" aimed at generating a new professional profile of the penitentiary officer defined as "Reflective Practitioner". An important motivation to introduce the methodological model of reflective practice into the course of work was the gaining of knowledge about achievements of the Scottish Prison Service College in the training of officers and managers of the Scottish Prison Service (SPS), where this approach being implemented in the context of workplace activities plays a key role (Morrison, 2017). Our determination in the use of this methodology is supported also by research papers of Polish scientists that - from an empirical perspective - attempt to check the benefits of reflectiveness treated as an ability improving the effectiveness of practical action. (PerkowskaKlejman, 2019).

What characterises this "Reflective Practitioner" in a general approach to his professional profile? Most generally, we can say that such individual has some inborn abilities, but he acquires certain skills also by training, and reflectiveness is the distinguishing feature of his attitude as a professional in his field. What can also be noticed about the figure/attitude of the Reflective Practitioner, is that he usually seeks best solutions through profound consideration and an in-depth analysis of his own actions in variable and unique situations of professional life, particularly with regard to work with other people. His multiple cognitive approach stimulates self-reflection on his current personal theoretical and practical preparation and he thoughtfully pursues the achievement of an even higher level of mastery in his profession. He uses in-depth reflection as an effective method and means of self-improvement in professional and general life. He tries to initiate proactively open reflective conversations in his nearest professional environment. He arranges a positive atmosphere around self-reflectiveness and interpersonal communication concerning intense reflectiveness on human condition. Among some employees of Academy of Justice, it is believed that the training and improvement of reflectiveness as one of the more important professional skills has a significant impact on the creation of cognitive self-regulation processes among prison service officers that directly lead to changes in their professional behaviours. Such actions for the creation of change in mentality can, therefore, be regarded as a good start to certain processes modernising the current Polish penitentiary system. The existing attempts to educate the staff according to the "Reflective Practitioner" model should be evaluated as a project with an absolutely high level of complexity; we can assume directly that this task is difficult, but exceptionally interesting and fascinating. 


\section{References}

Dewey J., (1988), How We Think, D. C. Heath \& Co. Publishers: Boston, New York, Chicago, 1910; https://www.gutenberg.org/ files/37423/37423-h/37423-h.htm

Fish D., (1996), Polish translation: Kształcenie przez praktyke [Learning through practice ], Wydawnictwa CODN, Warszawa.

Gołębniak D., Teusz G.(1996), Edukacja poprzez język [Education Through Language], Wydawnictwa CODN, Warszawa.

Gołebniak D., (1998), Zmiany edukacji nauczycieli, wiedza, biegłość, refleksyjność [Changes in Teacher Education, Knowledge, Proficiency, Reflectiveness], Wydawnictwo EDYTOR s.c., Toruń-Poznań.

Morrison, K.., (2017), Reflective Practice at the Scottish Prison Service [in:] Work Based Learning e-Journal, Vol. 8, No. 1, (2019).

Perkowska-Klejman A., (2019), Poszukiwanie refleksyjności w edukacji, studium teoretyczno-empiryczne [Looking for Reflectiveness in Education: A Theoretical and Empirical Study], Wydawnictwo Akademii Pedagogiki Specjalnej, Warszawa.

Schön D., (1984), The Reflective Practitioner. How Professionals think in Action?, Basic Books, New York.

Schön, D. (1987). Educating the reflective practitioner: Toward a new design for teaching and learning in the professions. San Francisco: Jossey-Bass.

Mariusz MALINOWSKI is an Assistant at the Academy of Justice in Warsaw. Specialising in distance learning, e-learning, modern technologies, complementary education, with focus on uniformed services.

ORCID ID: orcid.org/ 0000-0002-3877-8104

This work is licensed under the Creative Commons Attribution International License (CC BY). http://creativecommons.org/licenses/by/4.0/ 